\title{
Exploring the Challenges and Opportunities for Higher Education Institutions: Work Domain Analysis and Development of Strategic Options
}

\author{
Simon P. Philbin \\ Imperial College London, South Kensington Campus, London, United Kingdom
}

\begin{abstract}
This paper provides an exploration of the challenges faced by higher education institutions (HEIs) in the United Kingdom in the context of reductions in the level of public funding along with increased competition both on a national and international level. This competitive landscape has been reviewed through analysis of supporting data and information in order to identify the underlying trends impacting HEIs as well as the emerging opportunities especially in the context of research, technology development and industrial engagement. An extensive literature review has been carried out and was used as the basis for work domain analysis involving a structured process methodology to capture the domain specific drivers that contribute to academic strategy development especially relating to science and engineering areas. Subsequently, strategic options for operating in this landscape have been synthesized according to the research, education and knowledge exchange capabilities of HEIs. This strategy development includes discussion of a number of practitioner-oriented strategic options that may be adopted by HEIs to support the establishment of leading organizational capabilities, contribute to financial sustainability and deliver value for key stakeholders.
\end{abstract}

\section{INTRODUCTION}

Higher education institutions (HEIs) are of fundamental importance to the modern world as they are responsible for creating knowledge, developing skills and competencies for the workforce and generating value that underpins modern society [1]. Universities are able to act as engines for growth [2] through driving forward innovation and helping to support economic transformation as well as providing opportunities for investment and partnering with industry. Clearly there are significant knowledge and economic benefits [3] but universities do of course benefit students who are able to develop skills and qualifications that allow them to undertake graduate and postgraduate jobs requiring such an education as well as researchers and academic staff who are able to conduct research at universities. Universities provide the education that allows individuals to enter professions where they can deliver critical public services, such as healthcare, education, social and government (both regional and central) work. Furthermore and in the United Kingdom (UK) in 2009, it has been estimated that universities generated approximately $c a$. £60billion of economic output [4]. This analysis also found that universities are responsible for supporting in excess of $c a$. 670,000 jobs in the UK, either directly or indirectly, and in many regions universities are often the major employer and thereby have a stabilizing and positive economic impact on the region and the local inhabitants.
In regard to industrial interactions, universities are able to make a significant impact on many knowledge-based industries that rely on new research and technology and such industrial sectors include the pharmaceutical and life sciences sector, energy and power sector (including oil \& gas as well as nuclear power), advanced manufacturing (such as aerospace and automotive) as well as the creative, digital and related high tech sectors. Universities are therefore able to generate research outputs, contribute to the ideation process for new technologies and provide the highly skilled workforce needed by such sectors. However, universities face a number of important challenges, such as reductions in the level of public funding along with increased competition both on a national and international level. These challenges are accompanied by arising opportunities, such as those related to new information and communications technology (ICT) provision, the pursuit of new scientific, technology and engineering research areas as well as issues around how technology can best be implemented to improve the student experience and tackling the need for improved the efficiencies across large and complex university organizations.

Consequently this paper will explore some of the underlying trends impacting academic institutions in the UK and build on the position through examining some of the emerging opportunities especially in the context of research, technology development and industrial engagement. This academic institutional landscape will be reviewed through analysis of supporting data and information, allowing strategies for operating in this arena to be synthesized according to the research, education and knowledge exchange missions of HEIs. The paper will include discussion of a number of strategic options that may be adopted by HEIs to support the establishment of leading organizational capabilities, contribute to financial sustainability and deliver value for key stakeholders.

\section{ACADEMIC INSTITUTIONAL LANDSCAPE}

\section{A. Financial and economic landscape for universities}

The UK academic landscape includes a diverse collection of over 100 universities that provide undergraduate and in many cases post-graduate level education. In common with many other countries there are universities that have a mainly education focused remit and there are others that in addition to education also undertake research and these latter universities are often described as being research-intensive. Universities are also able to undertake other activities, sometimes referred to as 'third stream activities', which 
includes undertaking work (such as research, consultancy, testing or other services) for industrial companies as well as other commercial activities, such as engaging in the development of intellectual property (IP) through spin-out company formation and the negotiation of licensing agreements with companies. This third stream of work can be viewed as knowledge exchange or the translation of research and knowledge into wider value through providing commercial, societal or other such benefits.

Universities tend to be funded from a number of different sources, including governmental (which can be through so called block grants as well as from specific contracts or grants) as well as other sources such as charities, companies and from individual student tuition fees. From an international perspective, data can be considered on the level of investment that universities receive as part of a comparison between different countries. Accordingly Fig. 1 provides relative national expenditure levels from 2011 on tertiary education (i.e. post-secondary school education, including universities and further education colleges) for OECD (Organization for Economic Co-operation and Development) countries as a percentage of GDP (Gross Domestic Product) [5]. This data highlights that funding from both public and private sources of the UK tertiary education sector appears to be lagging many countries at just $1.2 \%$ of GDP, as compared to other countries such as Japan, Norway, United States and Canada with expenditures of $1.6 \%, 1.7 \%, 2.7 \%$ and $2.8 \%$ of GDP respectively. Different countries will of course have their own national level priorities towards expenditure on universities but this data underscores how the funding environment for universities varies internationally and specifically identifies the apparent weaker funding base for universities in the UK.

Focusing further on the income for UK universities, Fig. 2 provides a breakdown of funding, which highlights the range of funding types that is worth £28billion over the year 201112 [6] according to data from HESA (Higher Education Statistics Agency). Roughly a third of the overall income is from tuition fees and education contracts $(35 \%)$, which is provided from government support and also from tuition fees. Income also includes funding body grants, research grants and contracts that collectively accounts for nearly half of the total (46\%). Further, income from other sources accounts for around a fifth of the total (18\%) and finally, income from endowments and donations is at a very small level (1\%). Clearly overall this represents a significant level of funding but the financial picture is complicated by a number of underlying trends behind this data.

One such trend is the reduction in block grant funding that UK universities receive from HEFCE (Higher Education Funding Council for England (HEFCE) and this has been in decline over the last several years as evidenced by data in Fig. 3 [7]. This funding includes the recurrent grant (for teaching, research, moderation and the Higher Education Innovation Fund) and a smaller level of non-recurrent funding (for capital and other investment). The bulk of the reduction in funding is associated with the declining allocation for teaching, decreasing from $£ 4.71$ billion in $2009 / 10$ to 22.33 billion in $2013 / 14$.

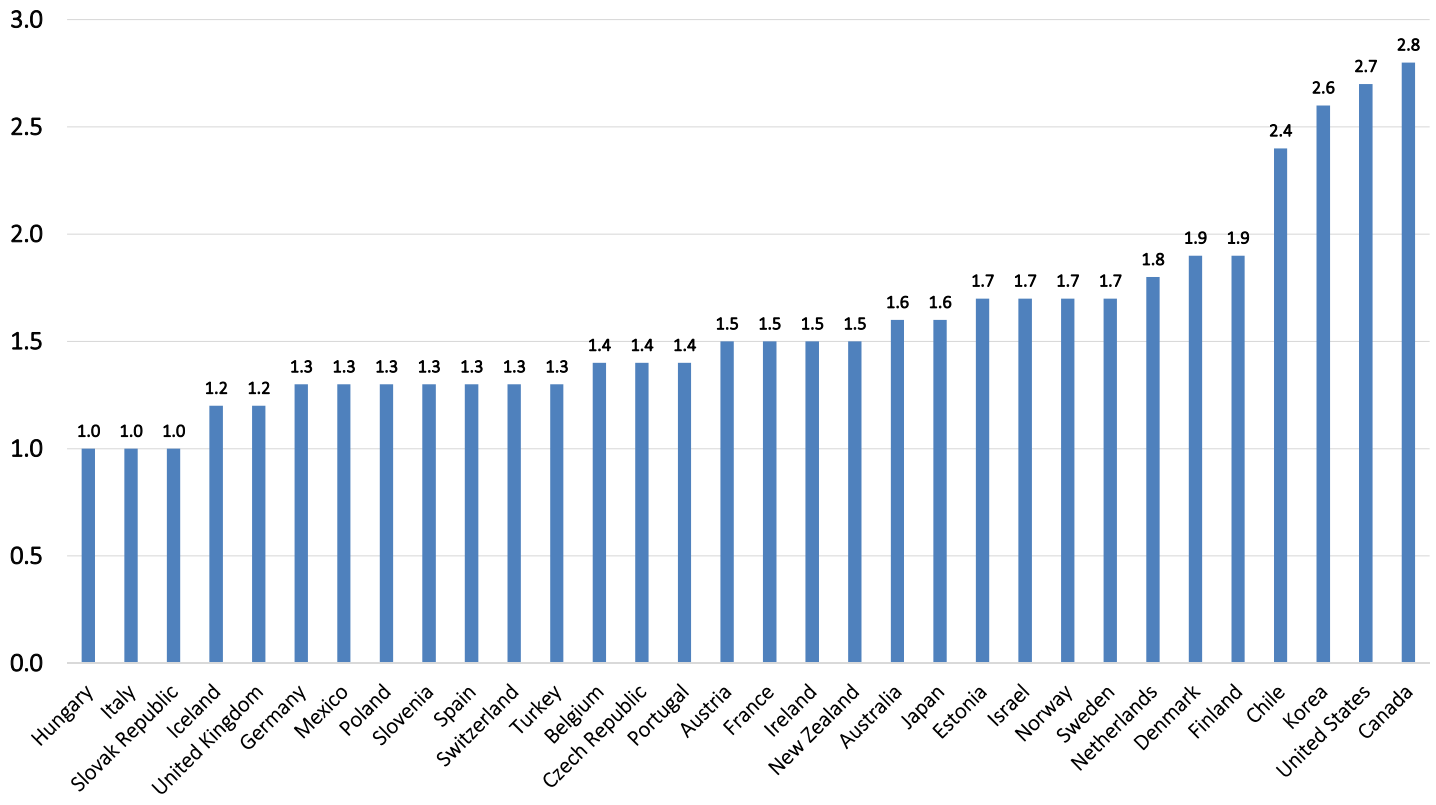

Fig 1. National expenditure on tertiary education for OECD countries in 2011 as a percentage of GDP [5]. 


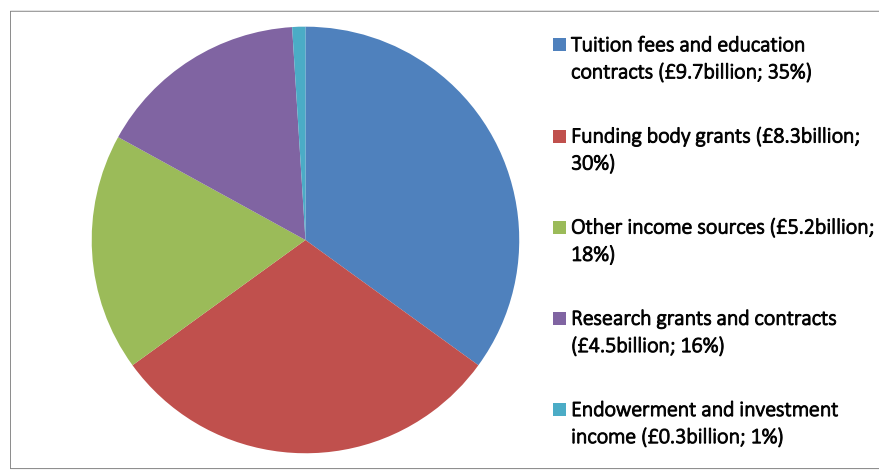

Fig. 2. Income to universities in UK, 2011-12 [6]

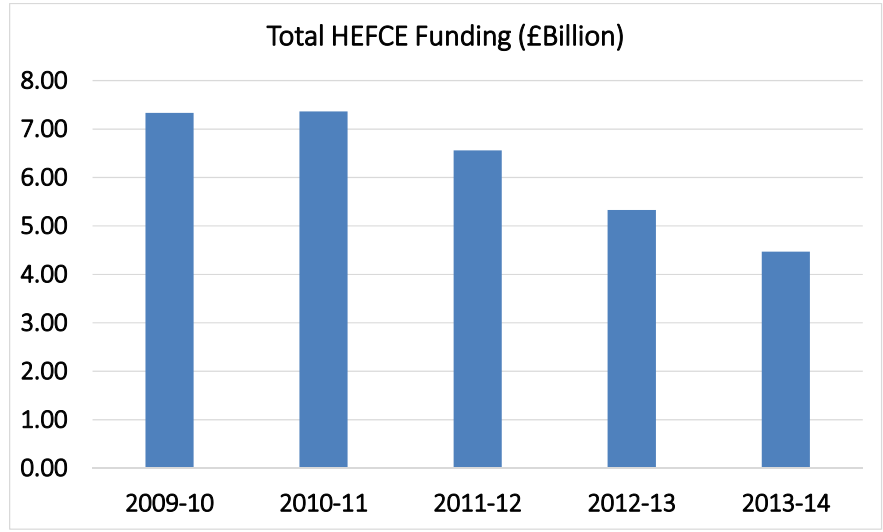

Fig. 3. HEFCE funding for UK universities [7].

However, this funding reduction has been offset by the increased level of funding universities in England receive from tuition fees, which from 2012/13 rose to a maximum level of $£ 9,000$ per annum [8]. Students in Wales and Northern Ireland pay a lesser amount whilst no tuition fees are applied for university degree courses in Scotland (unless the students are from outside Scotland in which case a fee is applied). Consequently, the proportion of university income from tuition fees from students for universities in England has been progressively increasing and this is helping to maintain the overall level of funding. Other areas of investment have been maintained or in some cases have increased slightly, such as the Higher Education Investment Fund (HEIF), which has increased from £130million in $2009 / 10$ to $£ 150$ million in $2013 / 14$. The HEIF investment provides support and underpins development of a range of knowledge-based interactions between UK universities and colleges with institutions in the wider world, which is focused on generating economic and social benefit for the UK [9].

In regard to other areas of funding, universities in England have also suffered significant reductions in capital investment, which in 2009 peaked at $c a$. £1billion but had fallen away to $£ 300$ million by 2013 [10]. This has resulted in universities having to place a higher priority on generating a financial surplus in order to fund capital investment into infrastructure development from internal funds. The ability for commercial activities to be undertaken by universities that have the capacity to generate such a surplus is therefore becoming increasingly important and especially in regard to maintaining infrastructure, such as laboratories and technical facilities as well as teaching and other academic facilities. These changes to the funding situation for UK universities and the varying levels of capital provision are leading to universities needing to adopt increasingly commercial approaches to management and also to take strategic decisions on which capabilities to develop and which are allowed to decline. For example, there is increasing pressure on laboratory based academic subjects that are more costly to provide when compared to non-laboratory based subjects.

\section{B. Broader landscape for universities}

Generally universities are large and complex organizations that are required to meet the needs of a range of stakeholders. Internal stakeholders include staff and students and ensuring development of these human resources is clearly important for a knowledge driven organization. Indeed students are increasingly being perceived as customers of universities [11], which has the potential to further change the student-academic relationship. Ensuring that students receive high quality tuition and appropriate 'value for money' will be important in this regard. Maintaining support to staff could include development of opportunities and career progression for junior researchers and early stage academics as well as ensuring professional and administration staff are also adequately accommodated.

Research-intensive universities need to ensure there is the necessary infrastructure to support scientific research [12], e.g. in disciplines such as chemistry, physics through to aeronautical engineering and medicine. An inability to ensure this technical infrastructure is available and properly maintained will significantly reduce the attractiveness of universities in regard to securing the services of new research and academic staff; in the case of chemistry for instance this infrastructure could include experimental laboratories as well as the required analytical equipment, such as nuclear magnetic resonance (NMR) spectrometers, mass spectrometry (MS) and high performance liquid chromatography (HPLC) equipment.

Once research has been undertaken there is the need to communicate the findings and knowledge dissemination is an important feature of academic work, whether this is publishing findings in academic journals or presenting results at academic conferences. Indeed the professional article has been viewed as being of fundamental to the modern system of scholarship; with publication of an electronic journal article arguably now being more important than any other form of research communication [13]. Other communication channels include seminars, webinars, lectures, blogging as well as contributing to governmental and industrial policy initiatives through being part of an advisory committee, panel or board. Access and participation in such channels needs to be maintained so that academic insights can be routed to the 
appropriate audience and for academic knowledge to be translated into benefits for external stakeholders, whether they are from governmental or industrial organizations. Capturing and measuring such benefits and wider societal impact for research [14] is an increasingly important feature of the academic landscape especially in regard to securing research grants funded by governmental agencies and funding councils.

An important channel for universities to translate research findings into industrial application and also provide commercial revenues to augment governmental funding is through partnering with industrial companies $[15,16]$. This can range from low level interactions, such as an academic providing advice or testing services via consultancy [17], through to much larger scale industrial support for a new academic research center, such as the BP funded Energy Biosciences Institute at the University of California Berkeley [18]. In this context there is a need for new business models that allow universities to structure different propositions that are attractive to industry, for example, through engaging with the pharmaceutical industry's approach towards open innovation [19]. This would then lead to a requirement for improved commercial practice within universities, where close support is provided to academic staff to allow new business models to be developed and successfully implemented. The size of a company can also influence how it works with universities [20], with smaller companies tending to focus on the need to solve a particular technical problem and larger companies being able to work with universities to develop overall technical competencies that will be of more strategic importance to the firm.

As indicated previously there is also growing competition between universities both on a national and international level. Universities now compete internationally for the best students and staff [21] but they also compete for research funds from global companies, such as those from the pharmaceutical and oil \& gas sectors. The question is: How will universities respond to this environment? Will they become entrenched and focus on core existing research and education areas without changing or adapting to market dynamics and other external factors? Or will they adopt increasingly modernized working practices, becoming more agile and better equipped to respond to emerging opportunities. Moreover, will they be able to leverage their traditional research and educational competencies to become increasingly adept at knowledge exchange and translation through exploring new modes of working with industrial companies and other stakeholder organizations. Key to navigating the financial challenges and being able to leverage commercial approaches will be the design and implementation of appropriate organizational strategies to enable resources to be deployed effectively and support the continued development of universities.

This landscape is also impacted by technology development and in particular development of ICT (information and communications technology) that has the potential to significantly change the way university education is delivered [22]. There is an expectation that greater levels of ICT adoption in higher education will lead to marked improvements in the effectiveness of teaching processes, although there is a continuing need for theoretical analysis leading to the development of pedagogically valuable tools based on ICT that can be used by practitioners in education [23]. Furthermore, new learning approaches involving ICT need to build on our existing understanding of human cognitive processes if they are to fully realize the potential. Also, adoption of social and digital media is likely to have an increasingly significant impact on how education is delivered across different subjects, such as those taught in university business schools [24].

As these changes to educational delivery are adopted there will no doubt be new approaches that emerge and which are leading; in such a scenario the universities that are able to adopt new practices quickly will potentially perform on a higher level than slower adopters. Winners and losers are likely and over the next few decades this could even result in the wholescale restructuring of the university sector including the possible closure of poor performing universities. Again this situation will be influenced by the development of appropriate strategies that will allow universities to adequately prepare and then adopt new technologies. This will likely include the need for new business models to support such technology adoption and these business models will need to accompany an increased focus on commercial best practice. Now that the overall academic institutional landscape has been reviewed it is appropriate to focus on deriving a strategic framework and specific strategic options that will help universities navigate this changing landscape.

\section{STRATEGY DEVELOPMENT}

\section{A. Strategy framework and research methodology}

The performance of university organizations will be contingent on the resources available ( $c f$. resource based view of strategy) as well as its ability to deploy those resources through an effective strategy. In this context, educational

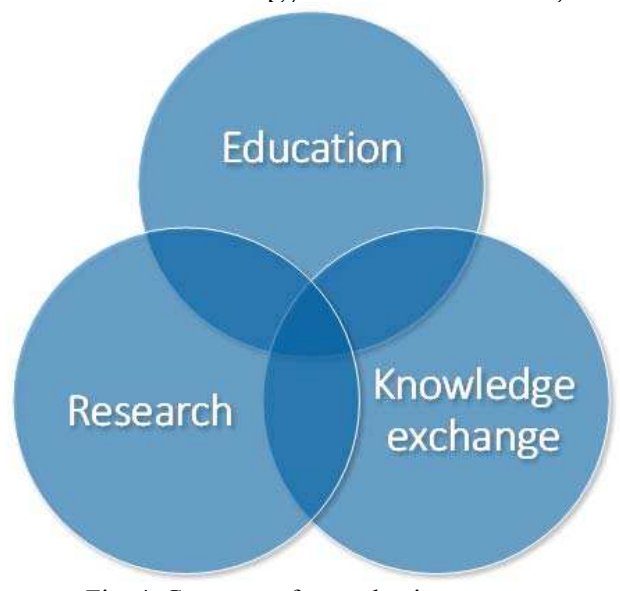

Fig. 4. Core areas for academic strategy. 
activities are core to a university [25] and for those that are research intensive clearly research will be a further core area [26]. Additionally, knowledge exchange and the translation of research outcomes into wider benefits should also be a core strategic focus for universities [27]. Consequently, it is useful to consider academic strategy development in terms of these three core areas or capabilities (see Fig. 4).

The development of these three core academic capabilities will need to be adaptable in terms of the environmental constraints (such as the availability of governmental funding and funding trends for research as well as availability of industry research funding) and also in regard to emerging opportunities, such as from adopting new ways of working and new business models for knowledge exchange. Further opportunities include capitalizing and leveraging developments in technology (ICT) and related digital technologies that have the capacity to significantly change the way education is delivered.

In order to synthesize a set of strategic options that will be of practical relevance to those involved in formulating academic strategy and future development, the systems-based work domain analysis (WDA) approach [28] has been utilized as a way of structuring the information and insights derived from the literature review reported in the previous section. Systems-based analytical tools, such as WDA, provide a holistic viewpoint that is particularly useful when considering the broader opportunities and strategic options for universities. WDA was selected following a review of other systems diagramming techniques, such as cause and effect modelling, system-of-systems modelling and use case diagrams. WDA provides a logical approach to structure information in a hierarchical manner and the technique underpins the research methodology described in this study.

WDA is the initial stage from the cognitive work analysis approach [29] and WDA has previously been used in different applications, such as modelling intensive care unit patients [30], air traffic controller weather displays [31], pasteurization process control [32] and the design of training systems [33]. WDA allows a description to be developed of the underlying constraints that govern the purpose and support the function of the system that is being analyzed. Use of this approach allows an abstraction hierarchy to be developed [34], which is based on five main levels of analysis that are linked by a series of 'means-ends' connections providing a visual representation of how the individual components have an impact on the overall domain purpose of the system. The five areas of analysis for the system are defined as follows:

A. Purpose and constraints: This is the strategic purpose and overall requirements of the system, including the high level constraints.

B. Values and priorities: The primary value drivers or core capabilities for the system, which can be used to assess the performance of the system.

C. Purpose-related functions: The functions that will be performed by the system to achieve the required purpose and according to the system domain and context.

D. Object-related processes: The processes carried out by the system in order to achieve the stated functions.

E. Physical resources: The resources required to underpin the functioning and operation of the system.

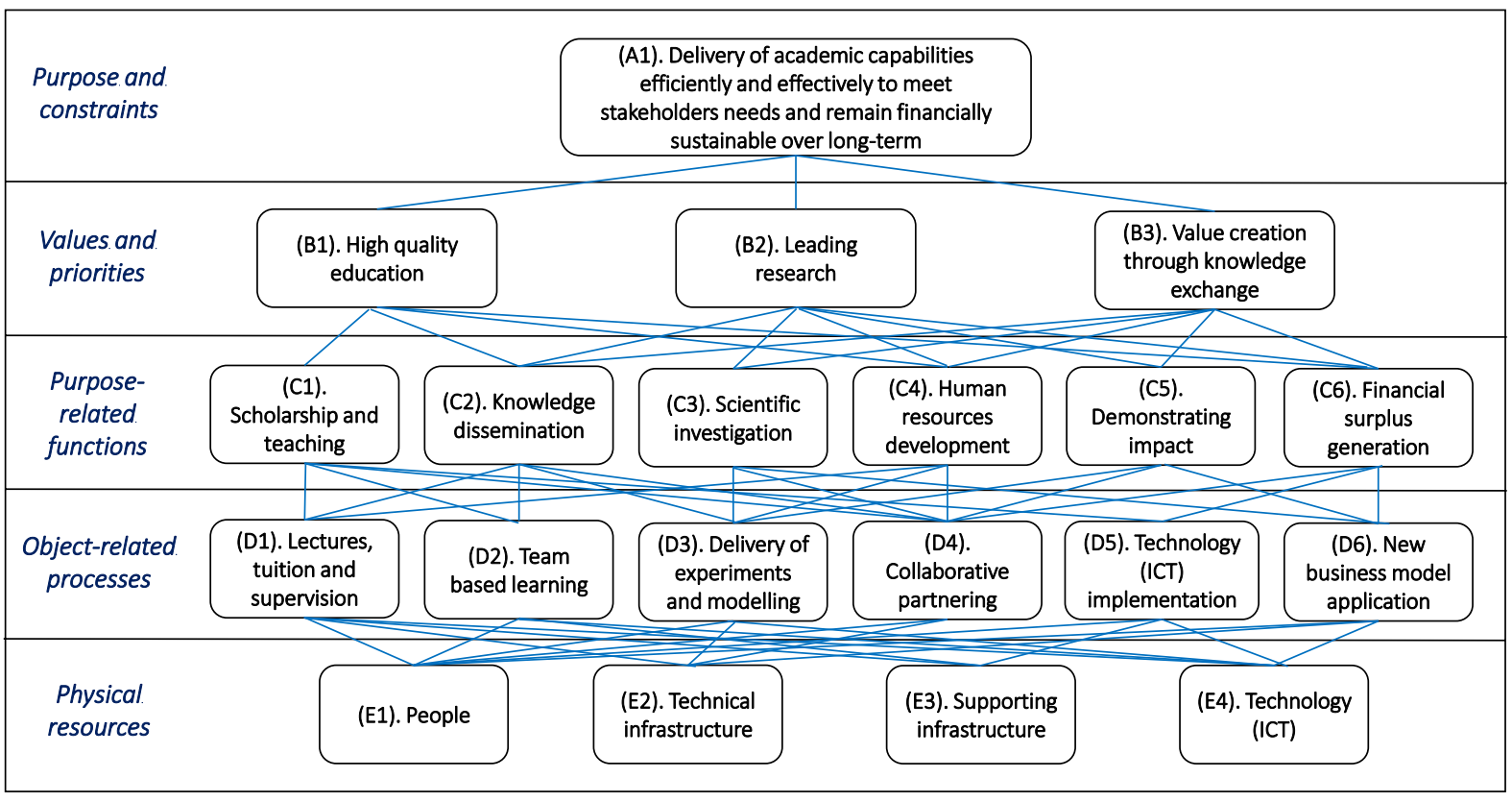

Fig. 5. Work domain analysis for academic strategy development. 
Review and analysis of the findings from the literature review on the academic institutional landscape allowed the work domain analysis for academic strategy development to be derived (see Fig. 5). Specific strategic options for the main academic capabilities of education, research and knowledge exchange have been synthesized through considering the findings from the WDA in Fig. 5 and are provided below according to the relevant capability area. The options are described in regard to supporting literature in order to validate the findings.

The WDA provided in Fig.5 highlights the hierarchy of factors (according to being functions, processes and resources) and how such factors underpin and relate to the values and priorities of universities. The level of interconnectedness between the factors is a further systems related feature, since delivery of many functions is reliant on over-lapping subsets of processes and resources.

\section{B. Education strategy options}

The strategic options identified for the education capability are provided in Fig. 6, which includes the relevant analysis frames and classifications derived from the WDA. For example, the strategic option 'Adoption of ICT' supports the primary academic priority (A1); which is based on the value driver to deliver high quality education (B1); through delivery to achieve scholarship and teaching (C1) and knowledge dissemination $(\mathrm{C} 2)$; via the processes of lectures, tuition and supervision (D1), team based learning (D2), technology (ICT) implementation (D5); supported by people (E1), supporting infrastructure (E3) and technology (ICT) (E4) resources. Further details of the strategic options are provided below including consideration of the requirements and activities associated with the implementation of the option.

(i). Adoption of ICT (information and communications technology)

There is significant scope for digital technologies to impact on education and change the way that education is delivered [35]. Concepts such as the virtual campus are arising, which has been defined as a "metaphor for the electronic teaching, learning, and research environment created by the convergence of several relatively new technologies including, but not restricted to, the Internet, World Wide Web, computer-mediated communication, video conferencing, multi-media, groupware, video-on-demand, desktop publishing, intelligent tutoring systems, and virtual reality" [36]. This potentially broad scope of ICT adoption gives rise to many possibilities for changing the dynamics of education provision and options for enhanced delivery channels in regard to effectiveness and efficiency. The use of technology to enhance education can also include an increasing use of social media [37] to underpin two-way communication between academic faculty and students.

Other trends include, for example, issuing students with a hand-held device that contains all the lecture notes preloaded, which will improve the process of note taking and allow students to be able to store all the required information for a given course in one easily accessible place. In regard to the adoption of technology and remote teaching it is unlikely that physical university campuses will disappear but technology-driven innovation is likely to be adopted alongside traditional forms of teaching, for example, through the increasing use of mobile applications ('apps') and other activities such as podcasting or webinars. The ultimate effectiveness of e-learning practice can be related to the

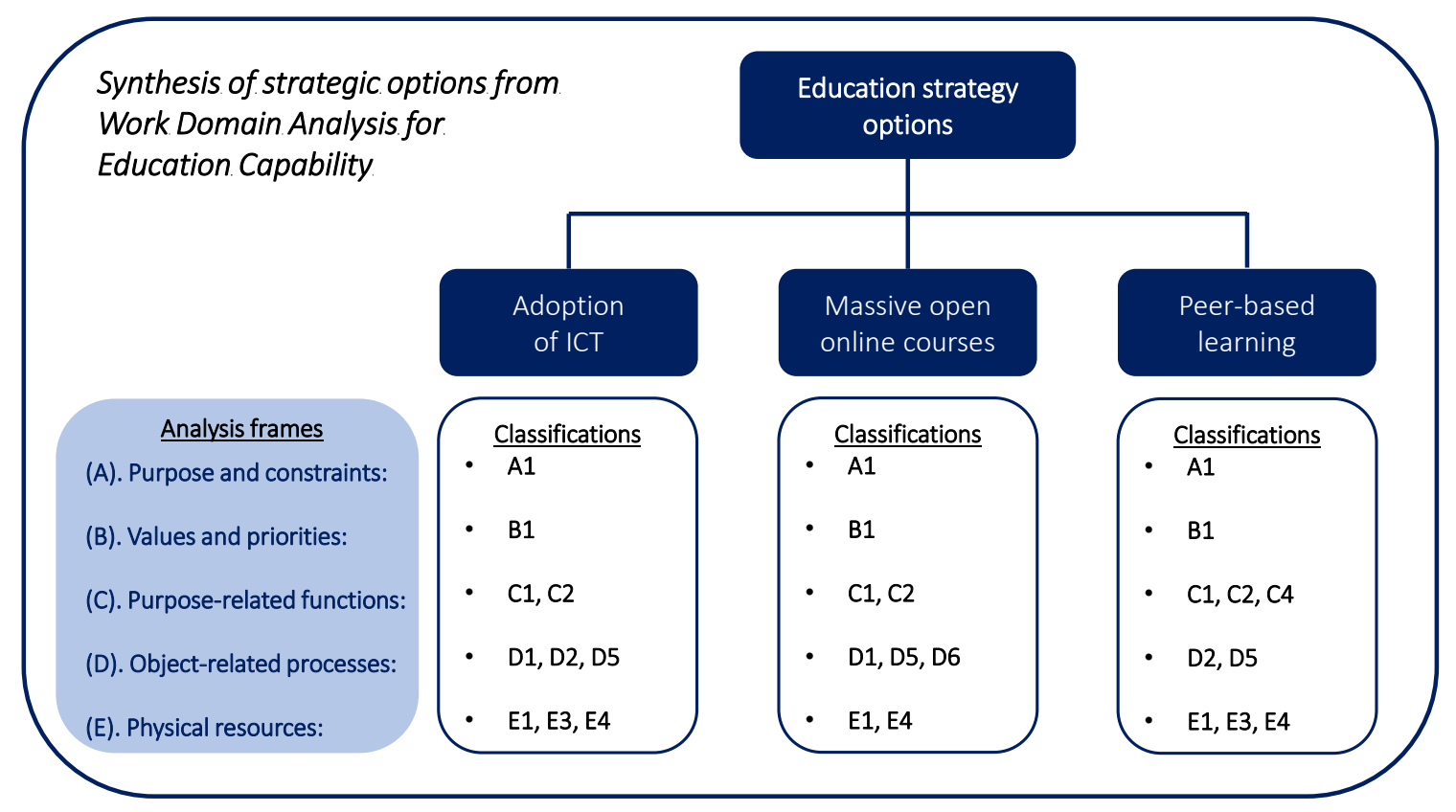

Fig. 6. Strategic options identified for the education capability. 
inputs and contributions of the actors involved, including teachers, students and university administrators. Furthermore, studies have highlighted how the adoption of elearning technologies can been related to a university's demographic characteristics [38].

\section{(ii). Massive open online courses (MOOCs)}

A specific application of information and communications technology is the delivery of so called massive open online courses or MOOCs [39] and student involvement in online courses at degree granting post-secondary institutions in the United States has increased from $10 \%$ in 2002 to $31 \%$ in 2010 as a percentage of total enrolment [40]. MOOCs have been launched by a number of leading universities, such as Harvard University and Stanford University [41] in USA, which in some cases are providing entire courses completely free of charge through an online portal. There are however a number of challenges for MOOCs in regard to how will certification be provided and how the course assessment will be carried out unless no such examination is taken.

Moreover, the underlying business case for online courses is still not fully understood as well as the strategic objectives for launching such a course, e.g. is it being delivered for altruistic aims of making the course available globally including potential students in developing countries, or is it to raise the profile of the university and help attract new students to the university's main campus based courses? There is also the need to consider how MOOCs will sit alongside existing conventional courses delivered by universities. Nevertheless MOOCs represent an exciting trajectory for the delivery of education by higher education institutions and the eventual delivery mechanism and supporting business model is likely to undergo further enhancement and refinement over the coming years.

\section{(iii). Peer-based learning}

Peer-based learning relates to the concept that students are able to educate each other and how the cognitive benefits are maximized for peers learning from each other [42]. Peer learning can promote a number of outcomes, including working with others, critical enquiry and reflection, communication and articulation of knowledge, understanding and skills, managing learning and how to learn as well as self and peer-based assessment [43].

Within the United Kingdom the Doctoral Training Centres (DTCs) that are funded by the Economic and Social Research Council (ESRC) include an interdisciplinary focus but are also designed to promote cohort and community building across the course program [44]. In this context groups of students register for postgraduate degrees and are able to collectively progress through their degree programs. The students are able to participate in group-based activities, such as workshops, team-based tuition, student led projects, interactive sessions and other activities that provide opportunities for the students to effectively learn not just from their own insights but also from the insights of other students.

Peer assisted learning is also used relatively widely in the provision of undergraduate medical education [45], which is largely through classroom-based learning but has also been investigated in clinical education environments although initial findings indicate that further research is needed in this area to fully understand the benefits and potential drawbacks of such an approach.

\section{Research strategy options}

The strategic options identified for the research capability are provided in Fig. 7, which includes the relevant analysis frames and classifications derived from the WDA. For example, the strategic option 'Research Excellence' supports the primary academic priority (A1); which is based on the value driver to undertake leading research (B2); through knowledge dissemination (C2), scientific investigation (C3) human resources development (C4) and demonstrating impact (C5); via the processes of delivery of experiments and modelling (D3) and collaborative partnering (D4); supported by people (E1) and technical infrastructure (E2) resources. Further details of the strategic options are provided below including consideration of the requirements and activities associated with the implementation of the option.

\section{(i). Research excellence}

Achieving research excellence is clearly an important objective for universities concerned with undertaking scientific and engineering research. Research excellence can be defined in different ways but it is usually related to the quality of the research, which can be determined through considering, for example, the number and quality of academic publications for a given area or faculty member as well as the resulting number of citations. Within the United Kingdom (as part of the Research Excellence Framework) for a number of years there has also been a focus on being able to demonstrate the 'impact' of research as an additional driver for excellence, with such impact being evidenced through contributions to industrial or economic development as well as wider societal and socio-economic benefits. Although some authors have cautioned as to the real benefits of this approach especially since measuring research excellence can be far from straightforward and also in regard to the perceived cost of administering the scheme [46]. An alternative view is to consider the benefits arising from research in the local geographical area as a way of capturing the holistic benefits for local stakeholders and such an approach carries particular merit for universities from emerging economies [47].

Developing and maintaining research excellence can also be highly dependent on a university's ability to attract and subsequently retain leading academic and research members of staff [48]. This will include a need to create a supportive environment to allow new faculty members to flourish as 


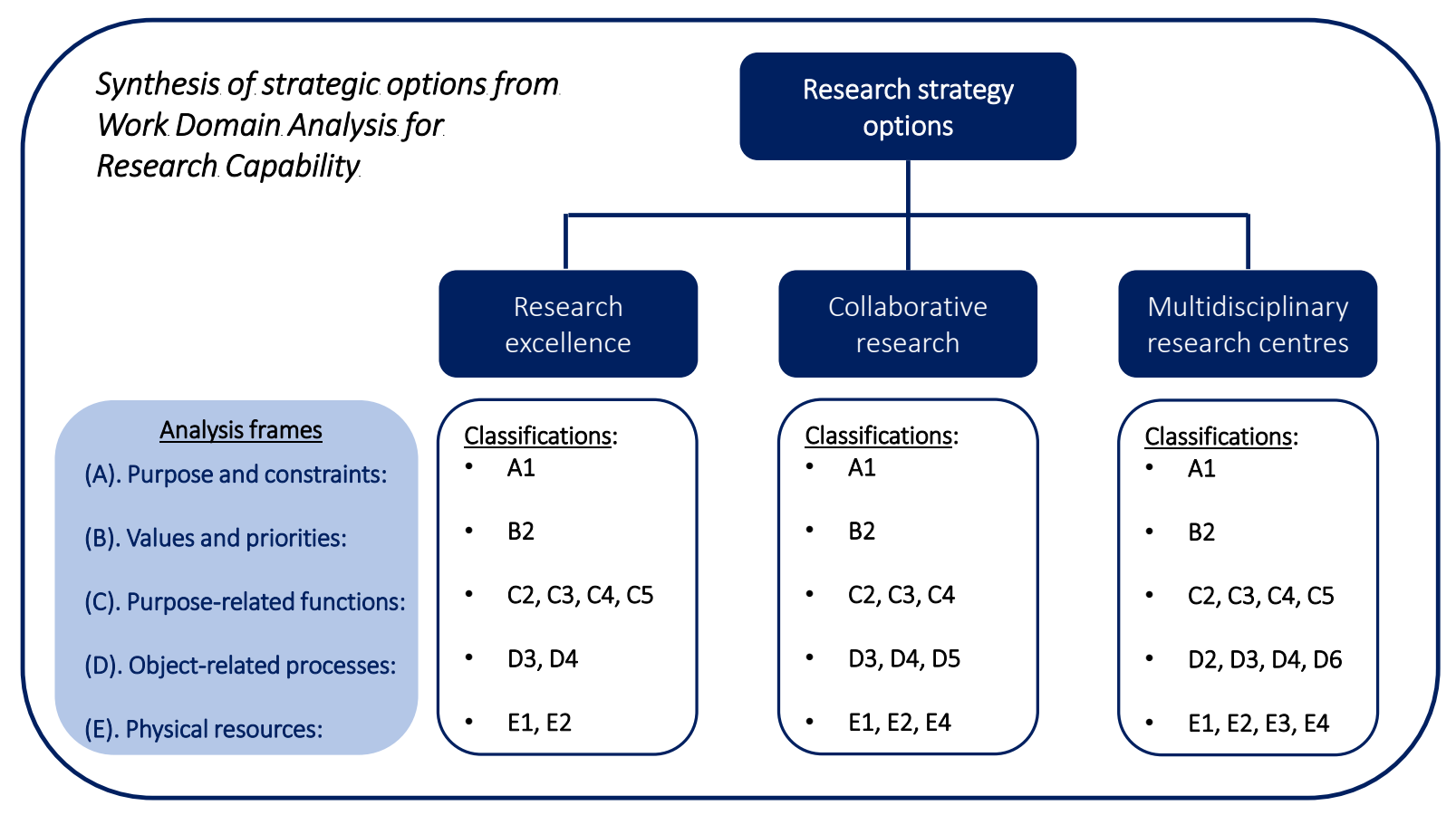

Fig. 7. Strategic options identified for the research capability.

well as providing opportunities for researchers to progress from, for example, research fellowship positions, through to permanent academic positions. Such mechanisms can help support 'home grown talent' in addition to the need to attract leading researchers and academics from other institutions and especially on an international basis. Moreover, many universities will deliberately seek to attract the very best academic staff from across the world and consequently there can be competition between institutions to secure the services of such individuals.

\section{(ii). Collaborative research}

Collaborative research has over a number of years become the norm for many universities and such activities are often promoted by governmental organizations, funding bodies and research councils [49]. Although sometimes collaborations have to bring together differing views they are nevertheless attractive mechanisms for pursuing demanding research objectives across different scientific areas (or disciplines). Integration of such differing perspectives can depend on factors such as having clarity on what the collaboration shall encompass as well as understanding the potential issues and external forces that may distort a collaboration over time and then developing appropriate mitigation actions [50]

In the healthcare sector collaborative approaches are often vital to underpin the overall research endeavor. In this regard work on a complex translational cancer research network consisting of different hospital-based clinicians as well as university-based researchers has been carried out in order to ascertain how the patterns of current and future collaborative projects can be influenced [51]. This research indicates that geographic proximity can be an important factor in regard to the selection of collaborators. In this context cross-site interactions can be enhanced through the adoption of improved virtual communications technology and also from increasing the level of social interactions between collaborators as a way to maximize available opportunities for collaborative team members to meet with others from different sites.

Collaborative research projects are also a major feature of research that is funded by the European Union, previously through a series of major Framework Programmes and currently as part of the Horizon2020 funding scheme that supports research across a broad range of areas, such as gene and cell therapy research [52]. Such projects are typically mandated to have a number of collaborative partners from across European countries as a way to ensure knowledge and economic benefits are shared across the members of the EU and affiliated partner countries.

\section{(iii). Multidisciplinary research centers}

Multidisciplinary research centers (and institutes) have been established at many universities as a mechanism to address a specific requirement for research through harnessing the contributions of multiple academic disciplines. Such centers are often established to encourage academics to develop new knowledge for industry and societal problems [53] that require a multidisciplinary approach as distinct from the traditional organization of universities according to academic disciplines. Studies of such centers have highlighted how there is often an increased emphasis on research coordination when compared to traditional academic departments where research management is normally decentralized and faculty members are free to pursue their 
own academic agendas [54]. This work also points to the need for robust reporting lines for center leadership including the key role of center governance as well as the pivotal contributions of the founding directors of the center who are often required to contribute not just their time and energy but also their personal gravitas and commitment to ensure a new center becomes established at the host institution.

After an initial period of funding from a governmental, charitable or industrial sponsor, multidisciplinary research centers are often presented with the challenge of becoming financially sustainable over the longer term [55]. In these situations centers will need to develop a robust business plan that captures the research objectives as well as the commercial and funding opportunities and needs of the center. Multidisciplinary research centers also offer scope to be based on a so called 'hub and spoke model' [56], where the hub is located at the main university and spokes are located at partner universities. This approach broadens the remit of the center even further to include disciplines and competencies from the host and partner universities, although when initiating such centers there needs to be care in the design of the center's organizational structure and processes, including governance and reporting arrangements.

\section{Knowledge exchange strategy options}

The strategic options identified for the knowledge exchange capability are provided in Fig. 8, which includes the relevant analysis frames and classifications derived from the WDA. For example, the strategic option 'UniversityIndustry Research Collaboration' supports the primary academic priority (A1); which is based value creation through knowledge exchange (B3); through delivery to achieve knowledge dissemination (C2), scientific investigation (C3), human resources development (C4) and demonstrating impact (C5); via the processes of delivery of experiments and modelling (D3), collaborative partnering (D4) and new business model application (D6); supported by people (E1), technical infrastructure (E2), supporting infrastructure (E3) and technology (ICT) (E4) resources. Further details of the strategic options are provided below including consideration of the requirements and activities associated with the implementation of the option.

\section{(i). University-industry research collaborative}

Research-intensive universities are likely to have well established relations with industrial companies although there can be much variation in the size and scope of such interactions. These collaborations will by design need to involve research that is aligned to industrial requirements, e.g. through academic consultancy, contract research and also from the industrial sponsorship of students and researchers [57]. Universities may pursue collaborations with companies for a number of different reasons that can offer a range of benefits, including gaining an improved insight into the academic research (especially in science and engineering), field testing the academic theory, supplementing funds for academic research, assisting the university's outreach mission, creating student jobs and internship opportunities, gaining knowledge that is useful for teaching and looking for further business opportunities [58].

Ensuring that the academic research remains aligned with the industrial requirements can be a particular challenge for university-industry collaborations as well as potential difficulties from agreeing the commercial arrangements for such relationships and specifically the negotiation of

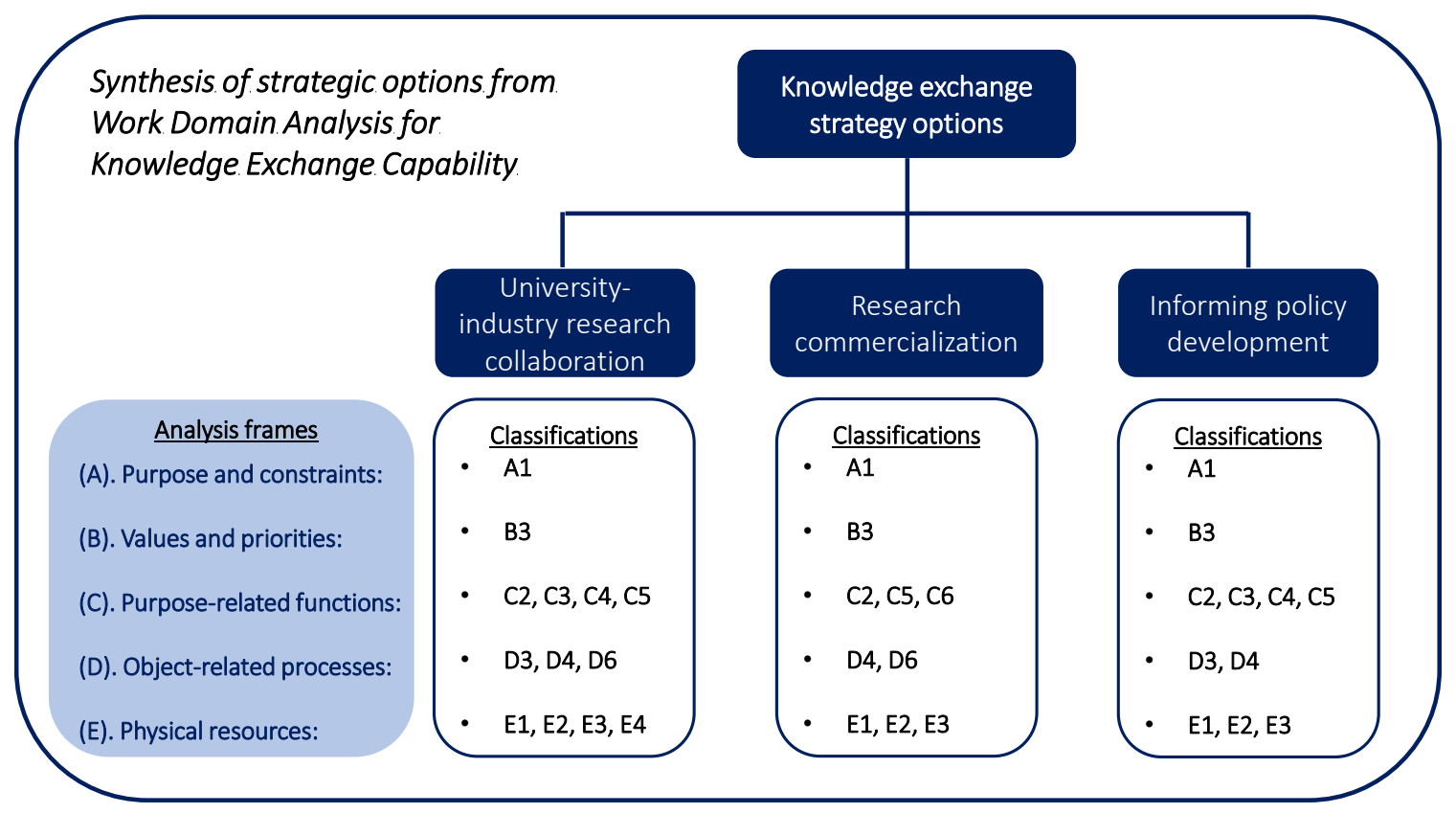

Fig. 8. Strategic options identified for the knowledge exchange capability. 


\section{Proceedings of PICMET '15: Management of the Technology Age}

intellectual property rights (IPR). On this matter, developing an overall commercial approach and agreeing the guiding commercial principles from the outset can be beneficial in regard to supporting the eventual negotiation of contractual terms and conditions [59]. Other considerations include the need to reconcile industry's generally shorter term view on the development of new products and services with academia's long-term view of fundamental research. Creating an awareness of this difference in priorities when developing a new collaboration can be particularly useful and this may include the use of technology readiness levels (TRLs) to define and articulate the research objectives of both parties. Companies will inevitably be focused on access to new technologies that have the potential to contribute to an improved competitive position for the company (e.g. through new product development), whereas universities have other needs, such as undertaking research that can be published in appropriate peer reviewed journals and this is particularly important for faculty members seeking tenure. These factors need to be considered carefully when setting up new university-industry research collaborations.

\section{(ii). Research commercialization}

The commercialization of academic research can be considered as a particular type of partnering between universities and companies but it is often viewed as a distinct activity area for universities and especially relating to science and engineering. Many universities have established technology transfer office (TTOs) to manage the research commercialization processes [60], including research patenting, negotiation of license agreements with partner companies as well as spin-out company formation. Research commercialization strategies are being pursued widely by universities and there is indication that university patenting is growing but this phenomenon appears to be largely heterogeneous across countries and disciplines [61]. Moreover, this work points to university licensing activities not being particularly profitable for many universities although some are successful in attracting substantial additional revenues.

The performance of academic entrepreneurship can have different determinants that include both entrepreneurial experience as well as private sector experience of the academic faculty [62]. Both these factors have been found to contribute positively to the development of business ideas based on research and furthermore, research-based business idea generation appears to increase at a faster rate for faculty members that have private sector work experience and whose positions encompass more time dedicated for research. In some countries, governments have established support programs that promote research commercialization and provision of such funding can help to accelerate the transfer of technology from universities to industrial organizations. However, there is still a need to develop appropriate indicators that are able to support the measurement of operational performance and the impact of the support schemes [63].

\section{(iii).Informing policy development}

Universities are increasingly being seen as having strategic roles in the global knowledge economy and this includes an ability to inform, influence and contribute to the development of policy on a range of different scientific and engineering subjects, such as energy, healthcare, security and other societal considerations. Universities can therefore be viewed as conduits that both on an organizational and individual (i.e. academic faculty member) level are able to participate in policy development for wider societal benefits that are beyond the primary research and education based activities carried out at the university [64].

In addition to establishing links with industry, universities and individual academics do understandably have extensive interactions with public sector organizations. Indeed research in the United Kingdom has estimated that overall around 53\% of academics engage with the public sector and the greatest area of interaction is in the healthcare arena that includes the UK's National Health Service [65].

Academic research itself can of course inform policy development and the ability to provide evidence-based analysis that promotes analysis and debate of societal issues is an important objective in many areas of research. For instance, through contributing to the public debate over the siting of renewable energy (RE) facilities, where there is often public reluctance to invest in such facilities that can subsequently result in difficulties for the expansion of the renewables sector [66]. In this example such research can be used to help develop mechanisms in which renewable energy policy can be structured in order to promote public support as well as engagement in the relevant issues.

\section{AGENDA FOR FUTURE INVESTIGATION}

Synthesis of the strategic options has provided a number of trajectories that universities are able to pursue in order to underpin the long-term sustainability of the academic institutions with a particular emphasis on STEM (science, technology, engineering and mathematics) areas. Through considering the nine strategic options that have been described it is evident that there is a need for further investigation and research according to the three main academic capability areas. Consequently, Table 1 provides a summary of potential research avenues that may be pursued. 
2015 Proceedings of PICMET '15: Management of the Technology Age

\begin{tabular}{|c|c|}
\hline $\begin{array}{l}\text { Academic } \\
\text { capability }\end{array}$ & Future research areas \\
\hline Education & 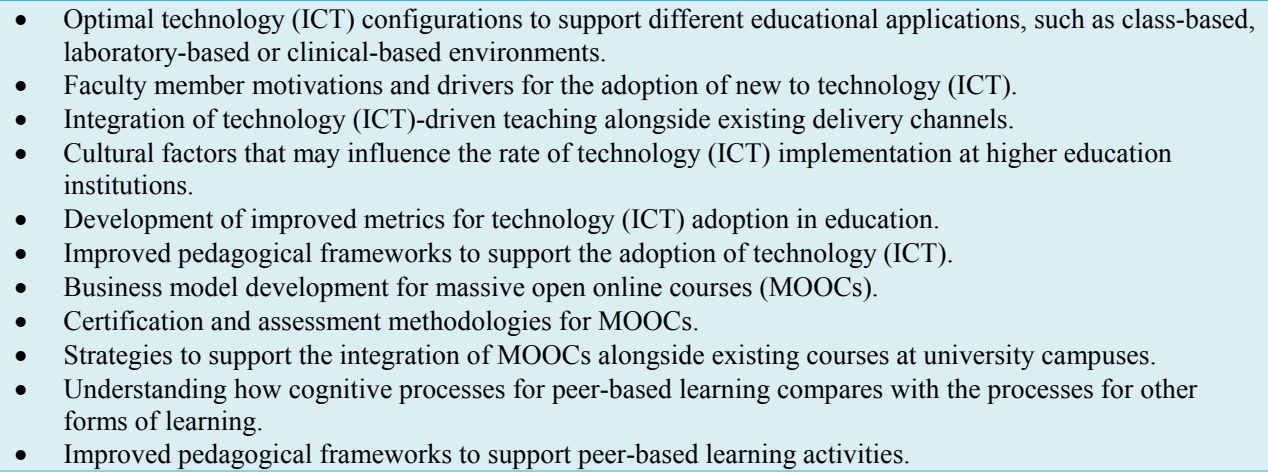 \\
\hline Research & 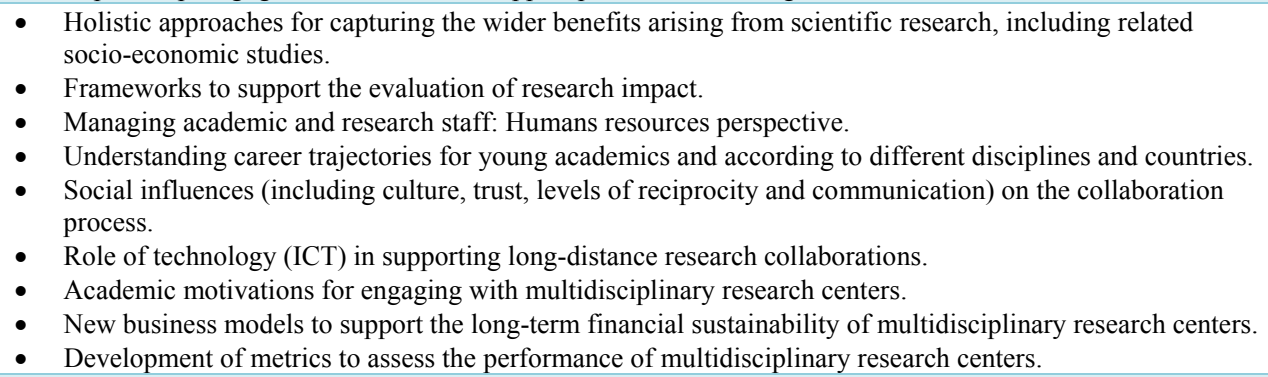 \\
\hline $\begin{array}{l}\text { Knowledge } \\
\text { exchange }\end{array}$ & $\begin{array}{l}\text { - Improved commercial frameworks to support the negotiation of university-industry research collaborations. } \\
\text { - Improved models for the allocation of IPR (intellectual property rights) for the benefit of both companies } \\
\text { and universities (i.e. realizing a 'win-win outcome'). } \\
\text { - Understanding the processes that support the adoption of academic research outcomes for NPD (new } \\
\text { product development) industrial applications. } \\
\text { Predictive financial models for understanding potential ROI (return on investment) from the } \\
\text { commercialization of applied research from universities. } \\
\text { - Motivations and antecedents for academic entrepreneurship. } \\
\text { - International comparative studies on the functioning and operations of university TTOs (technology transfer } \\
\text { offices). } \\
\text { - Leading indicators and metrics for governmental investment in promoting research commercialization at } \\
\text { academic institutions. } \\
\text { - Mechanisms to optimize the communication and application of evidence-based analysis from universities to } \\
\text { - Meapport policy and strategic decision-making. }\end{array}$ \\
\hline
\end{tabular}

\section{CONCLUSIONS}

Higher education institutions play an important role in economic and societal development, spanning the provision of education, delivery of research as well as knowledge exchange with key stakeholders including industrial companies. This paper has provided a detailed analysis of the potential strategic options that are available to universities, which have been synthesized through a structured approach based on the systems-based tool, work domain analysis. The hierarchical analysis carried out to develop the work domain analysis visual output was carried out through considering the findings from an extensive literature review focused on understanding the academic institutional landscape. This literature review focused on the case of universities in the United Kingdom (UK) through considering financial trends, which was developed further to discuss broader issues for the academic institutional landscape and especially related to science, technology and engineering. Although the research is grounded on the economic and financial conditions faced by universities in the UK, the authors feel that the insights and strategic options are equally applicable to universities both from and outside the UK. The initial analysis on the UK also helps to provide context to the research study as well as supporting data.

The work domain analysis (WDA) approach has allowed domain based development of nine strategic options, which have been uniquely classified according to the frames of analysis. This application of WDA and the corresponding classification system represents a novel approach for considering and subsequently generating strategic trajectories for university's to pursue. It is acknowledged that there will be other strategic options and the nine options that have been identified are not supposed to represent the entirety of development options for universities. Rather the identification of the nine options is an attempt to derive specific and practitioner-oriented approaches that can be pursued by universities concerned with the long term 
sustainability of the institution in regard to the adoption of ICT and in relation to the science and engineering subjects. The insights developed in this paper will be particularly useful to universities (and faculty members) with less well developed organizational strategies and such universities may not have a dedicated strategy function or department. These universities are encouraged to consider how development of the nine strategic options could impact on the opportunities and risks they face but they should also consider other options that may be aligned to their particular set of challenges and issues that need to be addressed.

As discussed previously, universities are presented with a number of challenges, ranging from responding to changing economic conditions and a tightening funding climate through to opportunities associated with new technologies. Responding to these challenges and opportunities requires a holistic appreciation of the issues and risks; academic strategy development according to education, research and knowledge exchange affords such a broad view. The nine strategic options amplify this broad scope through integrating social, technological, economic, legal and political considerations. There are also overlaps though between some of the drivers (e.g. research excellence and universityindustry research collaboration, or multidisciplinary research centers and informing policy development), which further underscores the complex nature of strategy development for universities.

The conceptual analysis provided in this paper has been linked extensively with supporting literature and a deliberate attempt has been made to include very recent literature citations in order to reflect the 'state of the art' in regard to the management of the academic enterprise. Nevertheless, the paper follows a process-based methodology supported by the use of the WDA technique. This process-based approach provides a systems view that allows a broad consideration of the purpose related functions (in the WDA this is C1 through to C6) as well as the object-related processes (in the WDA this is D1 through to D6). The analysis frames employed and corresponding classifications used in this paper also provide a taxonomy to characterize the strategic options identified, which can be further adapted and applied at different academic institutions.

The limitations for this paper lie with its conceptual approach, although the subject matter is broad and complex and in order to properly understand the dynamics that contribute to academic strategy development, the authors believe an initial conceptual approach is required to adequately address this complexity. Therefore, future work is proposed that will allow a more detailed investigation of academic strategy development. This includes addressing the areas for further investigation identified in Table 1. Moreover, this paper has utilized a systems approach based on a novel application of work domain analysis and it is proposed that further application of systems methodologies is employed in order to ensure all the contributing factors are understood as part of more detailed investigations. In this regard application of systems modelling techniques would be advantageous.

\section{REFERENCES}

[1] Smith, A.; "The intrinsic connection between research, innovation and growth", Journal of the Foundation for Science and Technology, vol. 20, no. 8, pp. 5-6, 2012.

[2] Harvard Public Affairs; Engines of Economic Growth: The Economic Impact of Boston's Eight Research Universities on the Metropolitan Boston Area, http://news.harvard.edu/gazette/2003/03.13/photos/EconomicReportfull.pdf, 2003

[3] Mansfield, E.; "Academic research and industrial innovation: An update of empirical findings", Research policy, vol. 26, no. 7, pp. 773$776,1998$.

[4] Universities UK; Universities UK Submission to the 2013 Spending Round,

http://www.universitiesuk.ac.uk/highereducation/Documents/2013/UU KsubmissionToThe2013SpendingRound.pdf, 2013.

[5] OECD; Education at a Glance 2014: OECD Indicators, http://www.oecd.org/edu/Education-at-a-Glance-2014.pdf, 2014.

[6] HESA; Higher Education Statistics for the UK 2011/12, https://www.hesa.ac.uk/, 2012.

[7] Bolton, P.; Higher education finance statistics, Standard Note: SN/SG/5440, Commons Library, 2014.

[8] Hutton, W.; "How will $£ 9,000$ tuition fees affect students? We'll be finding out", The Guardian, 2012.

[9] Public and Corporate Economic Consultants (PACEC); Strengthening the Contribution of English Higher Education Institutions to the Innovation System: Knowledge Exchange and HEIF Funding, http://www.hefce.ac.uk/media/hefce/content/whatwedo/knowledgeexch angeandskills/heif/HEIF11-15-FullReport.pdf, 2012.

[10] Universities UK; The funding environment for universities: an assessment,

http://www.universitiesuk.ac.uk/highereducation/Documents/2013/Fun dingEnvironmentForUniversities.pdf, 2013.

[11] Lomas, L.; "Are students customers? Perceptions of academic staff", Quality in Higher Education, vol. 13, no. 1, pp. 31-44, 2007.

[12] Johnson, R. E., Sherif, A. and Becker, F. D.; "Economics of university research laboratories-policy considerations", Construction Management and Economics, vol. 5, no. 4, pp. S31-S42, 1987.

[13] Schauder, D.; "Electronic publishing of professional articles: attitudes of academics and implications for the scholarly communication industry", Journal of the American society for information science, vol. 45, no. 2, pp. 73-100, 1994.

[14] Bornmann, L.; "Measuring the societal impact of research", EMBO reports, vol. 13, no. 8, pp. 673-676, 2012.

[15] Lambert, R; Lambert Review of Business-University Collaboration: Final Report, HM Treasury, http://www.eua.be/eua/jsp/en/upload/lambert_review_final_450.11515 81102387.pdf, 2003.

[16] Wilson, T.; A review of business-university collaboration, http://dera.ioe.ac.uk/13842/1/wilson.pdf, 2012.

[17] Docherty, I. and Smith, D.; "Practising what we preach? Academic consultancy in a multi-disciplinary environment", Public Money and Management, vol. 27, no. 4, pp. 273-280, 2007.

[18] King, C. J.; University roles in technological innovation in California, Center for Studies in Higher Education, https://escholarship.org/uc/item/3f0384w8, 2007.

[19] Bianchi, M., Cavaliere, A., Chiaroni, D., Frattini, F. and Chiesa, V.; "Organisational modes for Open Innovation in the bio-pharmaceutical industry: An exploratory analysis", Technovation, 31(1), pp. 22-33, 2011.

[20] Santoro, M. D. and Chakrabarti, A. K.; "Firm size and technology centrality in industry-university interactions", Research Policy, vol. 31, no. 7, pp. 1163-1180, 2002.

[21] Lepori, B., Seeber, M. and Bonaccorsi, A.; "Competition for talent. Country and organizational-level effects in the internationalization of 


\section{Proceedings of PICMET '15: Management of the Technology Age}

European higher education institutions", Research Policy, doi:10.1016/j.respol.2014.11.004, 2014.

[22] Sarı, A. and Mahmutoglu, H.; "Potential Issues and Impacts of ICT Applications through Learning Process in Higher Education", Procedia-Social and Behavioral Sciences, vol. 89, pp. 585-592, 2013.

[23] Gardenfors, P., \& Johansson, P. (Eds.); Cognition, education, and communication technology, Routledge, 2014.

[24] Thomas, M. and Thomas, H.; "Using new social media and Web 2.0 technologies in business school teaching and learning", Journal of Management Development, vol. 31, no. 4, pp. 358-367, 2012.

[25] Barth, M., Godemann, J., Rieckmann, M. and Stoltenberg, U.; "Developing key competencies for sustainable development in higher education", International Journal of Sustainability in Higher Education, vol. 8, no. 4, pp. 416-430, 2007.

[26] Altbach, P. G. and Salmi, J. (Eds.); The road to academic excellence: The making of world-class research universities, World Bank Publications, 2011.

[27] Graham, I. D., Logan, J., Harrison, M. B., Straus, S. E., Tetroe, J., Caswell, W. and Robinson, N.; "Lost in knowledge translation: time for a map?", Journal of continuing education in the health professions, vol. 26, no. 1, pp. 13-24, 2006.

[28] Naikar, N.; Work domain analysis: Concepts, guidelines, and cases. CRC Press, 2013.

[29] Naikar, N., Moylan, A. and Pearce, B.; "Analysing activity in complex systems with cognitive work analysis: concepts, guidelines and case study for control task analysis", Theoretical Issues in Ergonomics Science, vol. 7, no. 4, pp. 371-394, 2006

[30] Miller, A.; "A work domain analysis framework for modelling intensive care unit patients", Cognition, Technology \& Work, vol. 6, no. 4, pp. 207-222, 2004

[31] Ahlstrom, U.; "Work domain analysis for air traffic controller weather displays", Journal of safety research, vol. 36, no. 2, pp. 159-169, 2005.

[32] Reising, D. V. C. and Sanderson, P. M.; "Work domain analysis and sensors II: Pasteurizer II case study", International Journal of HumanComputer Studies, vol. 56, no. 6, pp. 597-637, 2002.

[33] Lintern, G. and Naikar, N.; "The use of work domain analysis for the design of training systems" in Proceedings of the Human Factors and Ergonomics Society Annual Meeting, vol. 44, no. 1, pp. 198-201, 2000.

[34] Jenkins, D. P., Stanton, N. A., Salmon, P. M. and Walker, G. H.; "Using work domain analysis to evaluate the impact of technological change on the performance of complex socio-technical systems", Theoretical Issues in Ergonomics Science, vol. 12, no. 1, pp. 1-14, 2011.

[35] Lea, M. R. and Jones, S.; "Digital literacies in higher education: exploring textual and technological practice", Studies in Higher Education, vol. 36, no. 4, pp. 377-393, 2011.

[36] Van Dusen, G. C.; "The Virtual Campus: Technology and Reform in Higher Education", ASHE-ERIC Higher Education Report, vol. 25, no. $5,2014$.

[37] Moran, M., Seaman, J. and Tinti-Kane, H.; Teaching, Learning, and Sharing: How Today's Higher Education Faculty Use Social Media, Babson Survey Research Group, 2011.

[38] Nawaz, A. and Kundi, G. M.; "Users of e-learning in higher education institutions (HEIs): perceptions, styles and attitudes", International Journal of Teaching and Case Studies, vol. 3, no. 2, pp. 161-174. 2011.

[39] Yuan, L., Powell, S. and CETIS, J.; MOOCs and open education: Implications for higher education, Cetis White Paper, 2013.

[40] Allen, I. E. and Seaman, J. Going the Distance: Online Education in the United States, 2011, Babson Survey Research Group, http://www.onlinelearningsurvey.com/reports/goingthedistance.pdf, 2011.

[41] Cooper, S. and Sahami, M.; "Reflections on Stanford's MOOCs", Communications of the ACM, vol. 56, no. 2, pp. 28-30, 2013.

[42] O'Donnell, A. M. and King, A. (Eds.); Cognitive perspectives on peer learning, Routledge, 2014.

[43] Boud, D., Cohen, R. and Sampson, J. (Eds.); Peer learning in higher education: Learning from and with each other, Routledge, 2014.

[44] Lunt, I., McAlpine, L. and Mills, D.; "'Lively bureaucracy? The ESRC's Doctoral Training Centres and UK universities", Oxford Review of Education, vol. 40, no. 2, pp. 151-169, 2014.
[45] Tai, J. H., Haines, T. P., Canny, B. J. and Molloy, E. K.; "A study of medical students' peer learning on clinical placements: What they have taught themselves to do", Journal of Peer Learning, vol. 7, no. 1, pp. 57-80, 2014.

[46] Martin, B. R.; "The Research Excellence Framework and the 'impact agenda': are we creating a Frankenstein monster?", Research Evaluation, vol. 20, no. 3, pp. 247-254, 2011.

[47] Ivey, P., Oliver, G. and Henry, M; "Evaluating the Impact of Research Produced by a Mission-Directed Emergent University", Journal of Research Administration, vol. 45, no. 2, pp. 73-88, 2014.

[48] Kim, S., Ross, B., Wright, A., Wu, M., Benedetti, T., Leland, F. and Pellegrini, C.; "Halting the revolving door of faculty turnover: recruiting and retaining clinician educators in an academic medical simulation center", Simulation in Healthcare, vol. 6, no. 3, pp. 168175, 2011.

[49] Smith, D.; "Collaborative research: Policy and the management of knowledge creation in UK universities", Higher Education Quarterly, vol. 55 , no. 2, 131-157, 2001.

[50] Bammer, G.; "Enhancing research collaborations: Three key management challenges", Research Policy, vol. 37, no. 5, pp. 875-887, 2008

[51] Long, J. C., Cunningham, F. C., Carswell, P. and Braithwaite, J.; "Patterns of collaboration in complex networks: the example of a translational research network", BMC Health Services Research, vol. 14, no. 1, pp. 225-235, 2014

[52] Gancberg, D. and Draghia-Akli, R.; "Gene and Cell Therapy Funding Opportunities in Horizon 2020: An Overview for 2014-2015", Human gene therapy, vol. 25, no. 3, pp. 175-177, 2014.

[53] Mosey, S., Wright, M., Clarysse, B.; "Transforming traditional university structures for the knowledge economy through multidisciplinary institutes", Cambridge Journal of Economics, vol. 36, no. 3, pp. 587-607, 2012.

[54] Bozeman, B. and Boardman, P. C.; Managing the new multipurpose, multidiscipline university research centers: Institutional innovation in the academic community, IBM Center for the Business of Government: Transforming Organizations Series, 2003.

[55] Feller, I, Ailes C. P. and Roessner, J. D.; "Impacts of research universities on technological innovation in industry: evidence from engineering research centers," Research Policy, vol. 31, no. 3, pp. 457474, 2002.

[56] Philbin, S. P., Jones, D., Brandon, N. P., Hawkes, A. D.; "Exploring Research Institutes: Structures, Functioning and Typology", Proceedings of PICMET'14 (Portland International Center for Management of Engineering and Technology) Conference, Kanazawa, Japan, 2014.

[57] Philbin, S. P.; "Managing University-Industry Research Partnerships through a Process of Alignment", Proceedings of PICMET'13 (Portland International Center for Management of Engineering and Technology) Conference, San Jose (CA), USA, 2013.

[58] Lee, Y. S.; "The Sustainability of University-Industry Research Collaboration: An Empirical Assessment”, Journal of Technology Transfer, vol. 25, no. 2, pp. 111-133, 2000.

[59] Burnside, B. and Witkin, L.; "Forging successful university-industry collaborations", Research-Technology Management, vol. 51, no. 2, pp. 26-30, 2008.

[60] Boehm, D. N. and Hogan, T.; “'A jack of all trades': the role of PIs in the establishment and management of collaborative networks in scientific knowledge commercialisation", The Journal of Technology Transfer, vol. 39, no. 1, pp. 134-149, 2014

[61] Geuna, A. and Nesta, L. J.; "University patenting and its effects on academic research: The emerging European evidence", Research Policy, vol. 35, no. 6, pp. 790-807, 2006.

[62] Gabrielsson, J., Politis, D. and Tell, J.; "University professors and early stage research commercialisation: an empirical test of the knowledge corridor theory", International Journal of Technology Transfer and Commercialisation, vol. 11, no. 3, pp. 213-233, 2012.

[63] Gulbrandsen, M. and Rasmussen, E.; "The use and development of indicators for the commercialisation of university research in a national support programme", Technology Analysis \& Strategic Management, vol. 24 , no. 5, pp. 481-495, 2012. 
[64] Deiaco, E., Hughes, A. and McKelvey, M.; "Universities as strategic actors in the knowledge economy", Cambridge Journal of Economics, vol. 36, no. 3, pp. 525-541, 2012.

[65] Hughes, A. and Kitson, M.; "Pathways to impact and the strategic role of universities: new evidence on the breadth and depth of university knowledge exchange in the UK and the factors constraining its development", Cambridge Journal of Economics, vol. 36, no. 3, pp. 723-750, 2012.

[66] West, J., Bailey, I. and Winter, M.; "Renewable energy policy and public perceptions of renewable energy: A cultural theory approach", Energy Policy, vol. 38, no. 10, pp. 5739-5748, 2010. 